\title{
The development of food consumption in the Czech Republic after 1989
}

\author{
M Dofkova, V Kopriva, D Resova, I Rehurkova and J Ruprich* \\ Centre of Food Chain Hygiene, National Institute of Public Health, Palackeho 1-3, 61242 Brno, Czech Republic
}

Submitted 22 December 2000: Accepted 19 March 2001

\begin{abstract}
Objective: To define the average food consumption per capita in the Czech population and to investigate food consumption development during the years of economic transition.

Design: Three studies based on the household budget survey (HBS) were conducted in the 1990s. The primary data originated from so-called diaries of reporting households loaned out from the Czech Statistical Office (CSO). The arranging of representative samples has been done and is guaranteed by the CSO. Complementary inquiry was conducted to supplement the HBS data. The average consumption of basic food groups is presented.

Setting: All regions of the Czech Republic.

Subjects: The primary data came from the years 1991, 1994 and 1997. The basic sample representing the Czech population included 420 households and was arranged with regard to the region, size and socio-economic type of households.

Results: The changes in food consumption during the 1990s were reflected, above all, in meat, milk and dairy products, added fats, fruit and beverages. The consumption of poultry meat, fish, fresh fruit and vegetables has increased. The proportion of added fats has changed in favour of vegetable fats. On the other hand, a negative feature may be the permanent reduction in milk consumption.

Conclusion: Most of the changes in eating patterns that appeared in the Czech population after 1989 can be interpreted as positive ones.
\end{abstract}

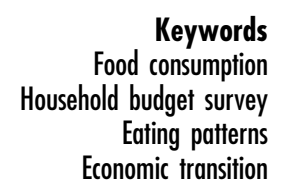

After 1989, the political and economic situation changed fundamentally in the Czech Republic as it did in other Central and East European countries. These changes were reflected in many areas, among others in nutrition ${ }^{1-3}$. Within a few years the eating patterns of the population changed considerably and it became very desirable to record the ongoing development. One of the methods of nutritional epidemiology that makes possible the estimation of food intake patterns is the analysis based on household budget surveys ${ }^{4}$. Although the household budget survey (HBS) had originally been drawn for the collection of economic information, the data can be used for basic nutritional evaluation as well ${ }^{5}$. In the 1990s the National Institute of Public Health (NIPH) launched three studies $^{6-8}$ describing the development in food consumption and the eating patterns of the Czech population in the period of economic transition by means of the HBS. The main objective of the project was to define the average food consumption per capita in the Czech population and in selected socio-economic groups, and to carry out a basic nutritional evaluation. This paper focuses particularly on changes and trends observed in the average food consumption.

\section{Materials and methods}

\section{Data collection}

The Czech Statistical Office (CSO) is involved in the collection of data on household income and expenditure, including food consumption. The data are used for determination of global availability per capita and are regularly published in publications of the Office? ${ }^{9}$. The Research Institute of Agricultural Economics conducts a deeper analysis of the HBS results, particularly in economic terms ${ }^{10}$. The structure of the data available from the two institutes, however, is not very suitable for nutritional evaluation and, as a consequence, neither for the estimation of potential health risks associated with nutrition of the population. As a result much more detailed processing of the HBS data was demanded. The NIPH is responsible for this issue within the framework of the grant study on 'Analysis of food consumption in the 
Czech Republic based on household budgets'. Study has been conducted three times virtually in the same extent, and this makes it possible to assess changes in the nutrition of the population that have taken place in the past 10 years. The primary data available are from 1991, 1994 and $1997^{6-8}$.

The primary data originated from so-called diaries of reporting households loaned out from the CSO. The selection of diaries from the CSO basic set and arranging of representative samples according to the requirements of the NIPH has been done and is guaranteed by the CSO. In each of the three investigations conducted, the basic sample representing the Czech population (420 diaries or households) was elaborated. It was arranged with use of weighting factors to obtain a representative sample with regard to the region, size and socio-economic type of households. In the second and third investigations samples of selected socio-economic groups of the population were analysed separately (in 1994 the households of farmers and pensioners and in 1997 also the households of employees and self-employed people). Table 1 presents the numbers of households included in the study in the respective years. The total number of elaborated diaries is lower than the sum of samplings because some of the diaries were incorporated both in the sample representing the Czech population and in the sample representing the socio-economic type of household.

The data in the diaries of reporting households are relatively detailed. All foodstuffs and beverages bought for the household or obtained from own production in the course of one month are recorded. The name of the food item, amount and price paid are always given. The amount of food is expressed either as the weight or as the number of pieces. In this way it is quite easy to determine the amount of the individual foodstuff purchased for the household. This is an advantage when compared with some European countries where only monetary value is available ${ }^{11,12}$. To exclude seasonal variability in food consumption, data collection went on during the whole year and the diaries from individual months were represented evenly in the sample. A limitation associated with the HBS method is the lack of information about foods consumed outside the household. Only data about the expenditure for this type of boarding and the number of food portions (lunches,

Table 1 Numbers of households included in the study

\begin{tabular}{lccc}
\hline Sample & 1991 & 1994 & 1997 \\
\hline Population of the Czech Republic & 420 & 420 & 420 \\
Households of employees & - & - & 239 \\
Households of self-employed people & - & - & 200 \\
Households of farmers & - & 200 & 200 \\
Households of pensioners & - & 150 & 150 \\
Total number of elaborated diaries & 420 & 612 & 787 \\
\hline
\end{tabular}

dinners) are available. That is why consumption outside the household has not been included in the results presented.

\section{Data processing}

All of the data from diaries were rewritten into the database and their logical range, consistency checking and aggregation were carried out. The consumption of about 500 items was investigated (with smaller deviations in the individual years). The average per capita daily food consumption was calculated for the population and for observed socio-economic groups; the proportion of households in the sample showing purchase of the respective foodstuff was defined and also the average per capita daily food consumption in this selected group was computed. The mean quantity of food available per capita daily was calculated by dividing the total amount of food taken into the household in the data collection period by the number of days of the period and the household size.

A check of food consumption data was also conducted by comparison between the requirements and intake of energy on the level of individual families. The energy intake for a representative sample of the Czech population was higher by $10 \%$, corresponding relatively well with the estimated losses and coverage of energy requirements.

\section{Complementary inquiry}

Inquiry was carried out within the framework of the study to have more information on the data found in dairies of reporting households. The 22, mostly structured questions were particularly concerned with culinary treatments of foods and shopping habits of the respondents. These habits have changed during past years especially due to a larger supply of goods on the market and a new wide network of supermarkets and hypermarkets. Data collection took place in November 1999. The questionnaire was distributed to 1200 households across the Czech Republic so that the sample would correspond with the set of households investigated through the HBS. Some interesting findings are mentioned in the text to complete results obtained from dairies. Detailed information can be found in a published monograph.

\section{Results}

Table 2 shows the average food consumption of selected groups of foodstuffs, reported in the study, expressed in grams per person per day. Amounts of food are given 'as purchased'. As mentioned previously, the results do not include food consumed outside the household that the HBS method is not able to define directly.

In terms of the consumption of meat and meat products, it was typical that after 1990 the preference of consumers for beef declined. Beef consumption in 1991 
Table 2 Average per capita daily food consumption in the Czech Republic (expressed in grams)

\begin{tabular}{lccc}
\hline Food group & 1991 & 1994 & 1997 \\
\hline Red meat & 67 & 57 & 66 \\
Beef and veal & 18 & 13 & 13 \\
Pork & 34 & 30 & 39 \\
Meat products & 52 & 52 & 50 \\
Poultry and poultry products & 25 & 30 & 41 \\
Fish and fish products & 7 & 11 & 13 \\
Milk & 165 & 173 & 150 \\
Cheeses & 15 & 17 & 19 \\
Other dairy products & 42 & 52 & 54 \\
Eggs & 33 & 33 & 32 \\
Total added fats & 39 & 45 & 46 \\
Vegetable oils & 7 & 12 & 14 \\
Vegetable fats & 9 & 16 & 18 \\
Animal fats & 22 & 18 & 14 \\
Sugar and sugar products & 55 & 58 & 63 \\
Sugar & 34 & 35 & 37 \\
Bread and pastry & 208 & 220 & 203 \\
Bread and rolls & 192 & 202 & 182 \\
Bakery products & 17 & 18 & 21 \\
Cereals and cereal products & 56 & 60 & 59 \\
Flour & 39 & 40 & 39 \\
Rice & 5 & 8 & 8 \\
Pulses & 3 & 3 & 4 \\
Potatoes & 154 & 109 & 129 \\
Vegetables & 116 & 105 & 122 \\
Fruit & 125 & 153 & 158 \\
Tropical and subtropical & 37 & 67 & 61 \\
$\quad$ fruit & 254 & 343 & 462 \\
Beverages & $141(7.7)^{\star}$ & $158(8.0)^{\star}$ & $170(9.0)^{*}$ \\
Alcoholic beverages (ml) & 164 & 274 \\
Non-alcoholic beverages & 97 & & \\
$\quad$ (ml) & & & \\
\hline
\end{tabular}

* Numbers in parentheses express respective amounts of ethanol in grams.

was $18 \mathrm{~g} \mathrm{person}^{-1}$ day $^{-1}$, while in 1997 it was only $13 \mathrm{~g}_{\text {person }}{ }^{-1}$ day $^{-1}$, nearly $30 \%$ less. The consumption of pork, traditionally the most frequently consumed red meat in the Czech Republic, was $39 \mathrm{~g}^{\text {person }}{ }^{-1} \mathrm{day}^{-1}$ in 1997 , i.e. $15 \%$ more than in 1991 . The consumption of mutton and lamb, an important part of the diet in some European countries, is close to zero in the Czech Republic. However, the consumption of meat products, particularly of soft salamis, frankfurters and sausages, is high. The basic raw material for their production is pork. The consumption of meat products did not change considerably in the 1990s and remained at the level of approximately $50 \mathrm{~g}$ person $^{-1} \mathrm{day}^{-1}$.

The increased interest of consumers in poultry meat and fish is satisfying. From 1991 the consumption of poultry increased by 64\% and in 1997 it was $41 \mathrm{~g}$ person $^{-1}$ day $^{-1}$. In particular, the consumption of chicken and turkey meat and of poultry specialities increased. In 1997 the share of poultry meat and poultry products in total meat consumption was 26\%, while in 1991 it was only $17 \%$. The consumption of fish and fish products by the Czech population is traditionally low; nevertheless, fish consumption increased slightly in the 1990s to $13 \mathrm{~g}$ person $^{-1}$ day $^{-1}$ in 1997 . This increase is attributed mainly to sea fish and canned fish products. The development in freshwater fish consumption is different and seems to fluctuate, apparently because of the market price. In 1997 it was only $2 \mathrm{~g}_{\text {person }}{ }^{-1}$ day $^{-1}$.

Pulses are an important source of proteins of vegetable origin. In spite of increased consumption in the 1990s, in 1997 the consumption of pulses was only $4 \mathrm{~g}^{\text {person }}{ }^{-1}$ day $^{-1}$. Compared with meat consumption this is very low.

Milk consumption was $150 \mathrm{~g}$ person $^{-1}$ day $^{-1}$ in 1997 , nearly 10\% less than in 1991. On the other hand, the consumption of cheese and other dairy products increased. Compared with 1991, cheese consumption increased by $27 \%$, to $19 \mathrm{~g}$ person $^{-1} \mathrm{day}^{-1}$. The most frequently consumed cheeses in the Czech Republic are hard and processed cheese. The consumption of other dairy products in 1997 was $54 \mathrm{~g}$ person $^{-1}$ day $^{-1}$, i.e. $29 \%$ more than in 1991. The most frequently consumed products of this food group are fermented dairy products, especially yoghurts. Through the complementary inquiry it was found that more than $85 \%$ of households preferred semi-skimmed or skimmed milk and about 30\% preferred cheeses with a low content of fat.

The added fat consumption in 1991-1997 increased by $18 \%$. However, this concerns only added fats of vegetable origin. The consumption of animal fat, on the other hand, decreased considerably. Butter consumption in 1997 was $9 \mathrm{~g} \mathrm{person}^{-1}$ day $^{-1}$, 36\% less than that in 1991. The consumption of melted pork lard decreased too (by 35\%).

Fruit and vegetables are important components of the diet, particularly because of their low energy value and relatively high content of important nutrients including vitamins and mineral elements. Whereas the consumption of fresh fruit and vegetables before 1990 was low, it has improved considerably lately ${ }^{10}$. Although the consumption has increased it has not yet achieved recommended values. The World Health Organization (WHO) ${ }^{13}$ recommends an intake of $400 \mathrm{~g}$ of fruit and vegetables (without potatoes) daily, whereas the consumption in the Czech population in 1997 was only $280 \mathrm{~g}$. The positive fact is that the supply and consumption are more varied, although vegetable consumption is still variable during the year. The most frequently consumed vegetables in the Czech Republic are fruit vegetables and brassicas. The share of fresh vegetables is high: in 1997 it was 88\% of the total consumption. On the other hand, potato consumption decreased by 16\% between 1991 and 1997. Fruit consumption in 1997 was $158 \mathrm{~g}$ person $^{-1}$ day $^{-1}$. In this group the consumption of virtually all commodities increased. The most important in this respect is that tropical and subtropical fruit in 1997 represented 38\% of the total consumption, i.e. $61 \mathrm{~g}_{\text {person }}{ }^{-1}$ day $^{-1}$, while in 1991 it was only $37 \mathrm{~g}$ person $^{-1}$ day $^{-1}$.

In 1991 to 1997 the total consumption of beverages increased markedly. However, alcoholic beverages developed differently to non-alcoholic ones. Whereas the consumption of alcoholic beverages remained more or less on the same level, the consumption of non-alcoholic 
beverages (fruit juices included) increased considerably. The consumption of non-alcoholic beverages in 1991 was $97 \mathrm{ml} \mathrm{person}^{-1}$ day $^{-1}$, while in 1997 it was $274 \mathrm{ml}$ person $^{-1}$ day $^{-1}$, an increase of $182 \%$. The reason for this is, above all, the substantially higher consumption of bottled table and mineral water, which became very popular among consumers probably due to better sensorial characteristics compared with tap water. The $100 \%$ increase in the consumption of fruit juices and the reduced consumption of syrup are positive phenomena as well.

The consumption of other groups of foodstuffs (eggs, bread, pastry, cereal products, sugar and confectionery) has not changed considerably since the early 1990s. Bread and pastry consumption in 1997 was $203 \mathrm{~g} \mathrm{person}^{-1}$ $\mathrm{day}^{-1}$, of which $182 \mathrm{~g}$ was bread and rolls and $21 \mathrm{~g}$ was bakery products. In terms of cereal products the highest consumption was of flour, i.e. $39 \mathrm{~g}_{\text {person }}{ }^{-1}$ day $^{-1}$. The consumption of breakfast cereals in Czech households is virtually negligible. However, data from other countries have shown that breakfast cereals are a profitable component of infant and adult diets ${ }^{14}$. Sugar consumption in the Czech Republic in 1997 was $37 \mathrm{~g}$ person $^{-1}$ day $^{-1}$ and is higher than in most West European countries ${ }^{15}$. The possible reason is that sugar is used for the home production of preserves, jams and cakes, especially in the households of pensioners.

\section{Discussion}

The reduction in the total volume of food consumed and changes in the structure of the food basket appeared after 1989 compared with the period before this year ${ }^{10}$. There are several reasons explaining these facts. The range of assortments of goods in shops is much wider, many new products have been introduced, and a lot of commercials have appeared in the media. Part of the population began to change its lifestyle. But the decisive factor was probably the economic transformation. After the introduction of VAT in 1990 and price liberalisation in 1991, consumer prices soared. Within a short time the prices of some foodstuffs multiplied several times ${ }^{9}$ and in the following years they continued to grow gradually. This is the reason why some customers are less interested in some foodstuffs. On the other hand, their preference for other commodities increased within a short time. The changes were reflected, above all, in the consumption of meat, milk and dairy products, added fats, fruit and beverages.

The lower consumption of milk, especially in families with children, can be considered as a negative feature in connection with the intake of calcium. The average calcium intake in the Czech population is only about $80 \%$ of recommended values $8,16,17$. On the other hand, there is a much larger supply of long-life products on the market today. The questionnaire survey showed that 67\% of households bought UHT treated milk. It is therefore probable that wasting milk or using it for purposes other than human nutrition in the households has been limited. This means that the actual reduction in consumption might be lower than the statistical data imply.

The increased added fats consumption is not favourable either, due to the fact that the total intake of fat in the Czech population exceeds the recommended value by $30 \%{ }^{8,16,17}$. The positive feature is that only vegetable fat consumption has increased, while the consumption of animal fats has decreased considerably. Consumers replaced animal fats with vegetable ones that newly appeared on the market. Margarine consumption in 1997 was $91 \%$ higher than in 1991. In the 1990s the households began to use new technologies in cooking meals, e.g. deep frying, more often. That is why only the amount of vegetable oils used to prepare the meal, not direct consumption, has increased. The complementary inquiry showed that about $50 \%$ of oil purchased by the households was not consumed (percentage was assessed on the basis of estimations of respondents) and it means that the actual consumption of vegetable oils was probably only about half the value calculated from diaries.

A frequent phenomenon of Czech households is own production of food and buying some commodities as a reserve. More than $60 \%$ of households supplement the purchased food, in most cases with fruit and vegetables, eggs and to a lesser extent meat, from their own production. The most frequently pre-stocked commodities are potatoes, purchased this way in $44 \%$ of households. Some households also buy fruit, some vegetables (e.g. cabbage, onions) and pork as a reserve. As both own production and the buying of food as a reserve are restricted to only part of the year, in this period their consumption appears to be higher. In the following months the actual consumption is apparently higher than the consumption based on the dairies of reporting households because some households are consuming these reserves. This fact creates an uncertainty that must be taken into account in the interpretation of the results.

A well-known limitation associated with the HBS method is the lack of information about foods consumed outside the household. At the same time this food could add significantly to the total consumption. Only data about the expenditure for this type of boarding are usually available in the HBS. In this respect it is an advantage in the Czech Republic that the dairies also provide information about the total number of portions consumed by members of the households in various catering facilities (canteens, school canteens, restaurants). This information could improve the estimate of the food proportion consumed outside the household. Using data from dairies and the questionnaire survey it was found that one person per month consumes approximately 10 portions of food (lunches, dinners) outside the household, that is an estimated $10-15 \%$ of the total consumption. More exact figures are not available. 
Another limitation of the HBS is that the results were obtained on the level of households and give evidence of the food consumption for the so-called reference (average) person. In this way it is impossible to determine the variability in food consumption among individuals. On the other hand, we must emphasise that, compared with methods that investigate food consumption on the individual level, HBS is much less demanding financially and in terms of organisation, and provides at the same time reliable information that can be effectively applied in the area of nutritional epidemiology.

\section{Conclusion}

Most of the changes in eating patterns that appeared in the Czech population after 1989 are positive. The composition of the foods consumed is much more varied. The consumption of poultry meat, fish and fish products, fresh fruit and vegetables has increased. The proportion of added fats has changed in favour of vegetable fats and oils. On the other hand, a negative feature may be the permanent reduction in milk consumption considering the possible insufficient intake of calcium in risk groups of the population (infants, pregnant and lactating women, and older people).

In spite of some limitations, the HBS method can be used effectively to follow the development of dietary patterns in the Czech population. The results can be applied in education to health, particularly in the area of prevention of nutrition-related diseases, in planning of agricultural production and also in assessing the dietary intake of additives and contaminants.

\section{Acknowledgements}

The study was realised with financial support of the Internal Grant Agency of the Ministry of Health (grant no. 4525-3). The Czech Statistical Office kindly provided the diaries of reporting households to the National Institute of Public Health.

\section{References}

1 Zunft HJ, Ulbricht G, Pokorny J, Sekula W, Szponar L, Abaravicius JA. Nutrition, physical activity and health status in Middle and East European countries. Public Health Nutr. 1999; 2: 437-41.
2 Chenet L, McKee M, Fulop N, Bojan F, Brand H, Hort A, Kalbarczyk P. Changing life expectancy in central Europe: is there a single reason? J. Public Health Med. 1996; 18: 329-36.

3 Cornia GA. Poverty, food consumption, and nutrition during the transition to the market economy in Eastern Europe. Am. Econ. Rev. 1994; 84: 297-302.

4 Nelson M. Household data and the National Food Survey. In: Margetts BM, Nelson M, eds. Design Concepts in Nutritional Epidemiology. Oxford: Oxford University Press, 1995; 120-30.

5 Trichopoulou A, Kanellou A, Lagiou P, Zintzaras E. Integration of nutritional data based on household budget surveys in European countries. Proc. Nutr. Soc. 1996; 55: 699-704.

6 Ruprich J, Cernoevicova M, Kopriva V, Ostry V, Resova D, Rehurkova I, Walterova D. The Czech Food Basket Survey 1991 [in Czech]. Prague: National Institute of Public Health, 1993.

7 Ruprich J, et al. The Czech Food Basket Survey 1994 [in Czech]. National Institute of Public Health: Prague, 1997.

8 Ruprich J, et al. The Czech Food Basket Survey 1997 [in Czech]. National Institute of Public Health: Prague, 2000.

9 Czech Statistical Office. Statistical Yearbook of the Czech Republic. Prague: Czech Statistical Office, 1999.

10 Stikova O, Sekavova H, Mrhalkova I, Fronek P. Consumption of Foodstuff and the Estimated Demand Development for Foodstuff Goods [in Czech]. Research Report 34. Prague: Research Institute of Agricultural Economics, 1996.

11 Trichopoulou A, Lagiou P, eds. Methodology for the Exploitation of HBS Food Data and Results on Food Consumption in 5 European Countries. Luxembourg: Office for Official Publications of the European Communities, 1997.

12 Trichopoulou A, Lagiou P, eds. Methodology for the Exploitation of HBS Food Data and Results on Food Consumption in six European Countries. Luxembourg: Office for Official Publications of the European Communities, 1998.

13 World Health Organization. Diet, Nutrition and Prevention of Chronic Diseases. Technical Report Series 797. Geneva: World Health Organization, 1990.

14 Ruxton CHS, Kirk TR, Belton NR, Holmes MAM. Breakfast habits in children. Nutr. Food Sci. 1994; 24: 17-20.

15 Byrd-Bredbenner C, Lagiou P, Trichopoulou A. A comparison of household food consumption in 11 countries. $J$. Hum. Nutr. Diet. 2000; 13: 197-204.

16 Directorate General Internal Market and Industrial Affairs. Nutrient and Energy Intakes for the European Community. Report of the Scientific Committee for Food. Luxembourg: Office for Official Publications of the European Community, 1993.

17 National Research Council, Food and Nutrition Board, Commission on Life Sciences. Recommended Dietary Allowances, 10th ed. Washington, DC: National Academy Press, 1989. 